\title{
A RARE CASE OF METASTASIS IN PARANASAL SINUSES
}

Jamila ${ }^{1}$, K. Valarmathi ${ }^{2}$, S. Ravi ${ }^{3}$, G. Selvambigai ${ }^{4}$

\section{HOW TO CITE THIS ARTICLE:}

Jamila A, K. Valarmathi, S. Ravi, G. Selvambigai. "A Rare Case of Metastasis in Paranasal Sinuses". Journal of Evolution of Medical and Dental Sciences 2014; Vol. 3, Issue 09, March 3; Page: 2208-2212,

DOI: $10.14260 /$ jemds/2014/2127

ABSTRACT: Most carcinomas affecting para nasal sinuses are primary carcinomas, metastatic involvement being a rare presentation compared with other sites like nose, naso pharynx, and palate, alveolar ridge, ethmoid, frontal and sphenoid. Secondary deposits are common in maxilla. There have been only few isolated case reports of thyroid tumour (3\%) metastatising to the para nasal sinuses. The most common thyroid malignancy is follicular carcinoma,(1) CT scan, radioactive iodine 131 scan and FNAC along with the clinical picture helps us in arriving at a diagnosis of metastasis to Para nasal sinuses from thyroid carcinoma.

KEYWORDS: Distal metastasis, para nasal sinuses, follicular carcinoma.

INTRODUCTION: Follicular carcinoma is the second most thyroid cancer accounting for $15-20 \%$ of thyroid malignancies. Follicular carcinoma metastasizes to lungs, bone, brain and soft tissues. para nasal sinuses are an extremely rare site of metastasis. $(2,3)$

The para nasal sinuses are involved by primary from renal cell carcinoma, bronchogenic carcinoma, breast carcinoma and prostatic carcinoma. In the world of literature, number of cases of secondaries in para nasal sinuses which have been reported are only 169. Thyroid carcinoma metastatic to the para nasal sinuses is extremely rare, with only 11 cases reported in the English and European literature.(9) Distant metastasis with primary thyroid carcinoma carries a poor prognosis.

CASE REPORT: A 76 year old female presented to the Oto-laryngology out-patient department, Chengalpattu Medical College Hospital with a swelling over the right maxilla for the past 6 months. The swelling was gradually increasing in size and was associated with pain. There was no history of voice change, dysphagia or weight loss. There was no history of previous surgery.

On clinical examination, a well-defined swelling of size $4 \times 3 \mathrm{~cm}$ was seen over the external aspect of right cheek without skin involvement. The palate on the right side showed a proliferative growth extending into the alveolus.

X-ray of the right maxilla showed haziness of right para nasal sinuses. CT scan showed a soft tissue lesion filling the right maxillary antrum with destruction of antral wall and alveoli extending into the para pharyngeal spaces, right ethmoid and sphenoid air cells. Expansile lytic lesion was noted in the right frontal bone with possible intracranial extension. A provisional diagnosis of carcinoma of Right maxilla was done and a punch biopsy was taken from growth in the alveolar region. On examination of the thyroid, a vague nodular enlargement of the thyroid was noted on the right side.

HISTOPATHOLOGY: Section shows squamous epithelium with underlying nests of tumour tissue composed of follicles lined by atypical cells. The follicles are seen invading the surrounding stromal tissue with foci of necrosis. 
A histopathological diagnosis of secondary carcinomatous deposit from follicular carcinoma thyroid was made.

DISCUSSION: Depending on its degree of invasiveness, follicular carcinoma has been subdivided into a minimally invasive and a widely invasive form. Minimally invasive follicular carcinoma is a grossly encapsulated tumor, often with a solid and fleshy cut surface. Since the diagnosis of malignancy depends entirely on the demonstration of blood vessel and/or capsular invasion, one should be very strict about these criteria. $(4,5)$ The blood vessel invasion is almost never evident grossly.

Widely invasive follicular carcinoma is the high-risk counterpart of the minimally invasive subtype. It shows widespread infiltration of blood vessels and/or adjacent thyroid tissue. It often lacks encapsulation altogether.

Bernstein et al (6) reviewed 82 cases with metastatic foci in the para nasal sinuses and reported that 40 patients had lesions in the maxilla, 15 in the ethmoids, 12 in the frontal sinus, and 6 in the sphenoid. The other sites of metastasis are nose, naso pharynx, palate and alveolar ridge. Compared with other sites like kidney (55\%), bronchus and urogenital ridge (11\%), breast (10\%) and gastrointestinal tract(6\%), only $3 \%$ of primary tumour was from thyroid. The commonest histology found was follicular carcinoma. Most cases of metastasis are from primaries below the clavicle.(7)

Nahum and Bailey proposed that retrograde spread of tiny emboli could occur to para nasal sinuses through vertebral venous plexus or through the lymphatics between thyroid and skull base and sinuses. CT scan is generally preferred diagnostic modality for detecting bony involvement, erosions and infiltration due to metastatic lesions. MRI gives better soft tissue resolution. Bone scanning with technetium-99 is important for staging of malignant tumors when there is concern for possible bone metastases aspiration cytology will help us to find out secondary involvement. A radioactive I-131 scan will reveal a functioning metastasis in the maxillary sinus. Finally biopsy taken from the lesion will give final conclusion.

Distant metastasis is the principal cause of death in cases of well-differentiated thyroid carcinomas. About $10 \%$ of papillary carcinomas and $25 \%$ of follicular carcinomas develop distant metastasis, with about $50 \%$ of patients having such metastasis at the time of diagnosis. The prognosis of these patients is poor, and over $50 \%$ of patients are likely to die within 5 years, irrespective of the histology of the tumor. ${ }^{[8]}$

Although metastasis to the para nasal sinuses is rare, pertinent symptoms such as facial swelling or bulge, epistaxis, nasal obstruction, visual disturbances and cranial nerve abnormalities should be investigated and treated.

\section{REFERENCES:}

1. Nahum A M, Bailey BJ. Malignant tumors metastasic to the paranasal sinuses: Case report and review of the literature. Laryngoscope. 1963; 73:942-53.

2. Meyer I, Shklar G. Malignant tumors metastatic to the mouth and jaws. Oral Surg.1965; 20: 35062.

3. Zachariades N. Neoplasms metastatic to the mouth, jaws and surrounding tissues. J Craniomaxillofac Surg. 1989; 17: 283-90. 
4. Chebib I, Opher E, Richardson ME: Vascular and capsular pseudo invasion in thyroid neoplasms. Int J Surg Pathol 2009; 17:449-451.

5. Fonseca E, Soares P, Cardoso-Oliveira M, Sobrinho-Simões M: Diagnostic criteria in welldifferentiated thyroid carcinomas. Endocr Pathol. 2006; 17:109-117.

6. Bernstein JM, Montgomery WW, Balogh K. Metastatic tumours to maxilla, nose and para nasal sinuses. Laryngoscope. 1966; 76: 621-50.

7. Zachariades N. Neoplasms metastatic to the mouth, jaws and surrounding tissues. J Cranio maxillofacial Surg. 1989; 17: 283-90.

8. Mazzaferri EL. Management of solitary thyroid nodule. N Engl J Med. 1993; 328: 553-559

9. Altman KW, Mirza N, Philippe L. Metastatic follicular thyroid carcinoma to the Para nasal sinuses: a case report and review. J Laryngol Otol. 1997 Jul; 111(7):647-51.

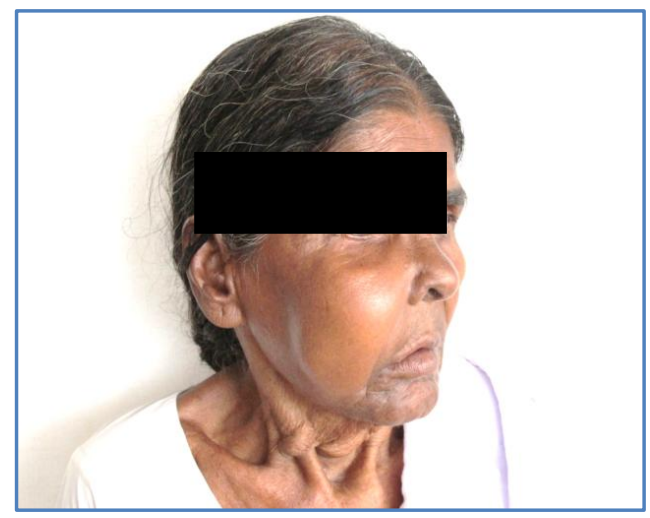

Fig. 1: Facial bulge seen on Clinical examination

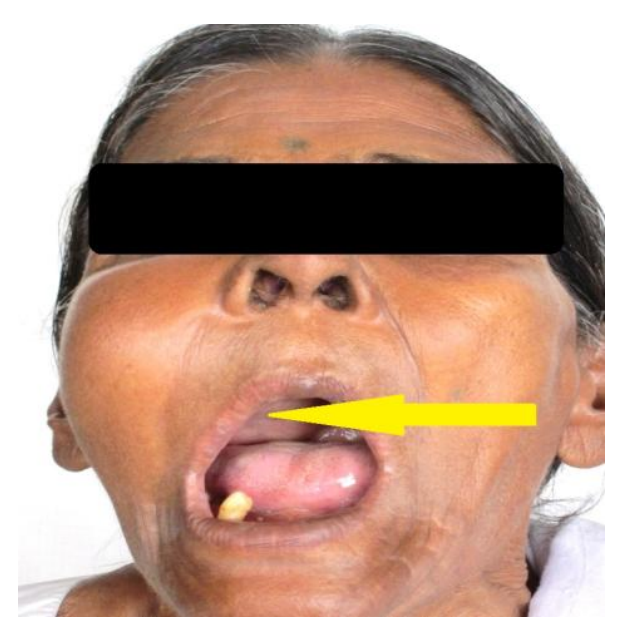

Fig. 2: Palatal swelling seen on oral examination 


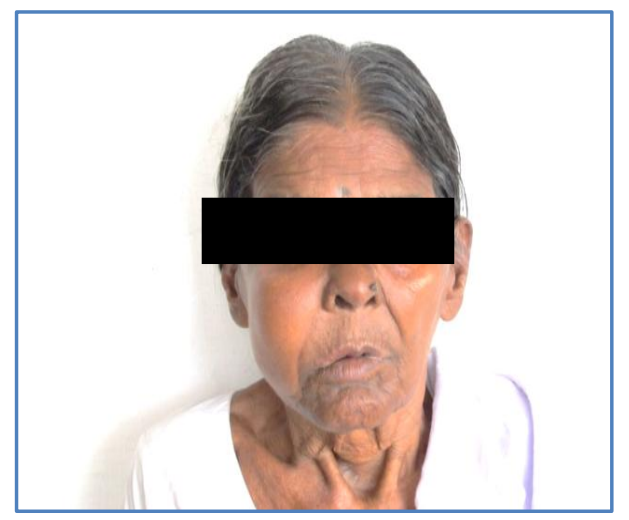

Fig. 3: Facial asymmetry with

Nodular enlargement of thyroid

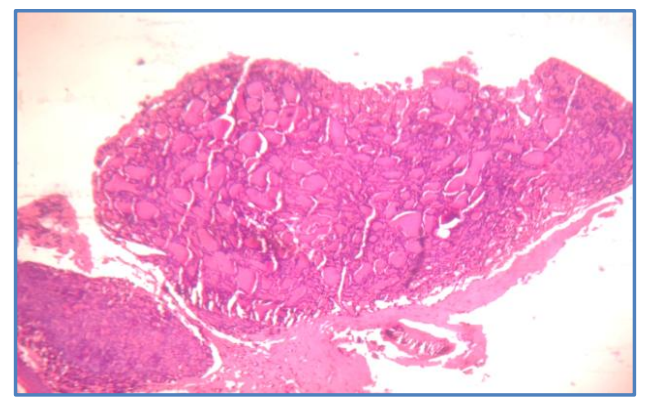

Fig. 4: Palatal biopsy showing sheets of follicles lined by atypical cells, H\&E, $5 \mathrm{x}$

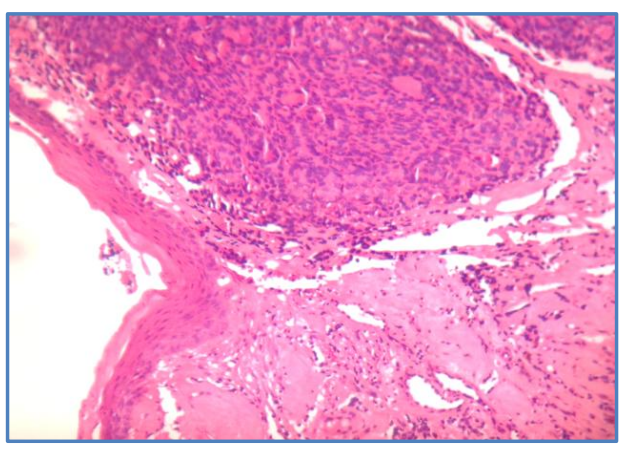

Fig. 5: Intact squamous mucosa with of underlying nests of thyroid follicles, 10x, H\&E

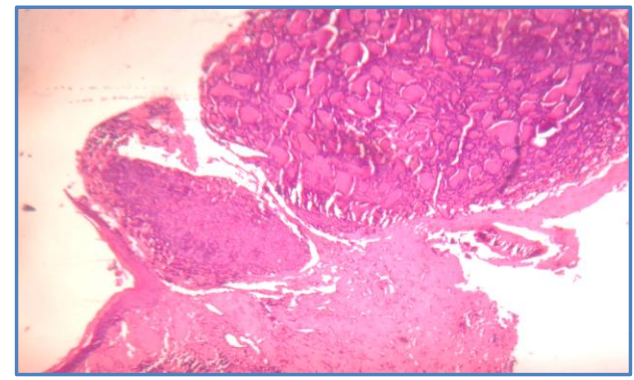

Fig. 6: Palatal epithelium enclosing nests follicles lined by atypical cells, 5x, H\&E 


\section{CASE REPORT}

\section{AUTHORS:}

1. Jamila A.

2. K. Valarmathi

3. S. Ravi

4. G. Selvambigai

\section{PARTICULARS OF CONTRIBUTORS:}

1. Professor, Department of Pathology, Government Stanley Medical College, Chennai, Tamilnadu, India.

2. Associate Professor, Department of Pathology, Government Stanley Medical College, Chennai, Tamilnadu, India.

3. Professor, Department of Pathology, Chengalpattu Medical College, Chengalpattu, Tamilnadu.
4. Associate Professor, Department of Pathology, Chengalpattu Medical College, Chengalpattu, Tamilnadu.

\section{NAME ADDRESS EMAIL ID OF THE CORRESPONDING AUTHOR:}

Dr. S. Ravi,

Professor of Pathology,

Department of Pathology,

Chengalpattu Medical College,

Chengalputta - 603001,

Tamilnadu, India.

E-mail: kumudharavips@gmail.com

Date of Submission: 27/01/2014.

Date of Peer Review: 28/01/2014.

Date of Acceptance: 19/02/2014.

Date of Publishing: 27/02/2014. 